\title{
How far are they coming from?
}

Samuel Otis-Chapados; Karolane Coderre; Stéphane Bolduc; Katherine Moore

Division of Urology, Department of Surgery, CHU de Québec, Université Laval, Quebec City, QC, Canada

Cite as: Can Urol Assoc J 2019 April 26; Epub ahead of print. http://dx.doi.org/10.5489/cuaj.5892

Published online April 26, 2019

$* * *$

\section{Abstract}

Introduction: In the province of Quebec, eight pediatric urologists practice in three tertiary centres covering large territories. To improve the availability of pediatric urology to distant families and to reduce the economic burden on them, we examined the chart of all patients attending the pediatric urological outpatient clinic. Our objectives were to evaluate the distance travelled by each urological pediatric outpatient and to report the most frequent urological referral complains.

Methods: From July 2016 to June 2017, we retrospectively reviewed the charts of all the 3609 pediatric patients seen in the outpatient urological clinic in CHU de Québec. We specifically focused on the travelling distance covered by families and the purpose of referral.

Results: Most patients were boys (78\%) and the mean age was 7.2 years. The average one-way distance traveled by each family was $69 \mathrm{~km}$. The patients came more frequently from Capitale-Nationale (63,7\%) and Chaudière-Appalaches (21,9\%), the closest regions. The most common reasons for consultations were postoperative followups (15\%), phimosis and adherences (14\%), enuresia (14\%), hydronephrosis (13\%), micturition disorder (11\%), and cryptorchidism and retractile testicles (8\%). Of all patients seen for phimosis or cryptorchidism, only $24 \%$ and $36 \%$ of them, respectively, were scheduled for surgery.

Conclusions: Phimosis, cryptorchidism, and voiding disorders are the most frequent pediatric urological reasons for consultation; primary care continuing medical education seems worthwhile. It would, perhaps, be more beneficial for all to have the pediatric urologists travelling to perform clinics and surgeries in distant regions to save more than $300 \mathrm{~km}$ round trip to several families. 


\section{Introduction}

In the province of Quebec, pediatric urologists are distributed between three tertiary centers: McGill University, Université de Montréal and Université Laval. Each center, in order to offer the best urological care, must cover a large part of the 1667 millions km² territory and several administrative regions. Unfortunately, some cities are several hundred kilometers away from the closest tertiary center. In this context, the children and their families must skip work and school to attend their urological appointment, which implies lost of incomes. They should plan for travel expenses including gas, food and lodging. It is a socio-economic problem that also concerns other specialities. On October 2012, telephone consultations became a legal fee-for-services benefit by the Régie de l'Assurance Maladie du Québec (RAMQ). ${ }^{1}$ This was one possible answer to address the issue.

Telemedecine is emerging as a solution to overcome long distances and to decrease patient and families absenteeism. ${ }^{2-3}$ However, telemedecine is time-consuming, still not well defined in several provinces and it presents a frontier for physical examination. In pediatric urology, the physical examination is often the centerpiece of a consultation and for many complaints; it is capital and decisive for treatment recommendation and to establish surgical indications.

The main objective of our study is to measure the distance travelled by each pediatric patient visiting the outpatient urology clinic and ultimately, to bring strategies to improve the situation. Our secondary endpoint is to report the most frequent urological referral complaints to develop better guidelines for first-line providers.

\section{Methods}

We retrospectively reviewed all the charts of the 3604 outpatient's consultations performed by the two pediatric urologists in CHU de Québec between July $1^{\text {st }} 2016$ and June $30^{\text {th }}$ 2017. All inpatient consultations, patients for which data were missing or patients followed beyond their eighteenth birthday were excluded from the study. All information was already available and accessible through the medical software used in CHU de Québec without contact necessary with the families. We recorded demographic information for all patients: sex, age, reason for referral, patient's address to determine their origin, one-way distance traveled by each family and the ratio of children needing surgery for their urological conditions. All data were compiled and descriptive data analyses were performed. This study is a qualitative analysis of the information collected, which did not necessitate elaborate statistical analysis. The institution and the research ethics board approved data collection as a medical quality review. 


\section{Results}

A total of 3604 outpatient's consultations were analysed for a one-year period. Among all these visits, $78 \%$ of the patients $(n=2825)$ were boys and $22 \%(n=784)$ were girls. The mean age at consultation was 7,2 years (SD 2.3y). The one-way distance traveled by those families for their urological appointment was on average $69 \mathrm{~km}$ (median $21 \mathrm{~km}$ ). In our study, it is important to note that there were 6 patients included who came from New Brunswick.

Using the postal code of each patient's residence, we determined the geographical origin of all the patients who were referred for urological consultation in Quebec City. (Fig. 1). Without surprises, most of the patients lived in the two closest regions to CHU de Québec: 63,7\% Capitale Nationale (region 03) and 21,9\% Chaudière-Appalaches (region 12) (Fig. 2). However, Saguenay-Lac-St-Jean (region 02) and Bas-St-Laurent and Gaspésie (regions 01 and 11) represent respectively 3,5\% and 3,7\%. For each of these regions, this represents $18.9 \%$ of our patients who travelled more than $200 \mathrm{~km}$ round trip for their urological appointment. One hundred and seven (107) patients travelled more than $400 \mathrm{~km}$ one-way for their medical visit, which implies more than one-day off-work and extra lodging expenses. These lodging expenses can be partially reimbursed by the government upon request.

We recorded more than 60 different reasons for consultations (Table 1). The most common purpose for pediatric urological visit was post-operative follow-ups ( $\mathrm{n}=529$, $15 \%)$. The first reason for urological referral was phimosis $(n=512,14 \%)$. The second most frequent reason for consultation was nocturnal enuresis ( $n=501,14 \%$ ) followed by hydronephrosis ( $\mathrm{n}=479,13 \%)$, micturition disorder including incontinence, urinary retention, overactive bladder and dysfunctional voiding $(\mathrm{n}=384,11 \%)$ and cryptorchidism ( $n=289,8 \%)$ respectively. These six urological reasons for appointments represent $75 \%$ of all the consultations in the one-year study period.

The children were referred by their family doctor, their paediatrician, a community urologist or a nurse practitioner for surgical issues. Phimosis and cryptorchidism are the two most common urological pathologies requiring surgery. Of the 512 consultations for phimosis only 123 patients were ultimately scheduled for a medically indicated circumcision (24\%) (Fig.3). Others were physiological adhesions or successfully medically treated phimosis using corticosteroid cream. On the other hand, there were 289 consultations for cryptorchidism and 105 of them needed a surgical correction (36\%), the remaining being retractile testis, an issue that can be difficult to evaluate using telemedicine (Fig. 4). 


\section{Discussion}

We are the firsts, to our knowledge, to report precisely over a one-year period the distance travelled by families to attend exclusively a tertiary pediatric urological outpatient clinic. Previous Canadian reports from Shivji et al. in Edmonton and Bator et al. in Toronto focused on travel expenses related to a pediatric surgical clinic and the family attitude toward telemedicine alternatives. ${ }^{2-3}$ Knowing that the greater the distance from home to the clinic, the greater the expenses and the parent's absenteeism, we aim to characterize the pediatric population referred to a single tertiary outpatient urological clinic in the Province of Quebec. To decrease the economic burden on patients, the Régie de l'Assurance Maladie du Québec (RAMQ) partially reimburses patients for the distance traveled if they live more than $200 \mathrm{~km}$ away from the hospital that can provide the care for their child. ${ }^{4}$ Families can also declare their travel expense in their annual taxes. This leads to significant societal costs. These long distances traveled also imply significant indirect costs for the families. Out of the pocket costs for accessing health care like parking, lodging, meals and time away from work and school cause significant financial burden. The Toronto group in 2015 measured costs for urological or general pediatric surgery consultation. In their survey, they confirm that more than $74 \%$ of parents missed, at least, half a day of work. Furthermore, nearly $70 \%$ perceived overall costs of a clinic visit to be medium to high. These numbers give an idea of the impact experienced by the families in our study. Even though, only 18,5\% of their patients travelled more than 200 $\mathrm{km}$ round trip to attend their appointment, 33\% of them spent more than 50\$ CAD not including work missed, which for several families could substantially affect their budget. In comparison with their study, 18,9 \% of our patients travelled more than $200 \mathrm{~km}$ round trip.

Our study demonstrates that the majority $(63,7 \%)$ of the patients seen for urological pediatric consultation came from the Capitale Nationale region (03), which includes Quebec City. However, the Capitale Nationale region covers $18640 \mathrm{~km}^{2}$ and comprises cities as far as $215 \mathrm{~km}$ away. In fact, more than $50 \%$ of the patients from the 3604 studied consultations traveled more than $40-50 \mathrm{~km}$ to attend their appointment for an average one-way distance of $69 \mathrm{~km}$ (median $=21 \mathrm{~km}$ ). The second region most frequently deserved by the two pediatric urologists is Chaudière-Appalaches (21,9\%) just across the Saint-Lawrence River that also extends to the American borders. In addition, patients from remote communities sometimes have to fly more than $1000 \mathrm{~km}$ to attend the clinic.

Several solutions can be introduced to overcome distance and associated fees. Telemedecine could be a remedy for large territories. In 2015, le Collège des médecins du Québec has published guidelines for the use of telemedecine. ${ }^{5}$ Furthermore, in 2012, the RAMQ created a fee-of-services for telemedecine consultations. ${ }^{6}$ There are only few 
studies about telemedecine in pediatric surgery specialities. ${ }^{2-3,7}$ The centers in those studies had large territories to cover and they evaluated the usefulness of telemedecine and the level of satisfaction of families. All reported a high satisfaction with both preoperative and postoperative evaluation from families and practitioners. Some other studies evaluated telemedecine uniquely in urology. ${ }^{8-10}$ All of them reported reduced costs and time for patients and improved patient's satisfaction and facilitates access to health care system. None of them have demonstrated a reduction in mortality, morbidity or major complications. Telemedecine in urology is particularly useful for problems like lithiasis, surveillance of renal cysts and chronic management of micturition disorders when imaging and initial evaluation can be provided by the referring center.

Consultations or preoperative evaluations with physical evaluation are not situations where telemedecine best serves the urologist and the patient. Nevertheless, telemedecine in pediatric urology could be worthwhile for pathologies such as incontinence, hydronephrosis, micturition disorder and postoperative evaluation. However, this type of practice brings confidentiality, billing and surely productivity adjustments and must be avoided if physical examination is necessary as with phimosis and cryptorchidism, respectively representing $14 \%$ and $8 \%$ of the referrals of our referrals. $^{11}$

Another possibility could be for the pediatric urologist to visit specific community centers once or twice a year taking example on what the CHU de Québec's adult urologists are already doing. Looking at our numbers, providing pediatric urological consultation in Saguenay-Lac-St-Jean (3,5\%) and Bas-St-Laurent and Gaspésie (3,7\%) would reach a great amount of patients and reduce considerably their travel distance, as Rimouski (Bas-St-Laurent) is 300 km away from Quebec City and Saguenay (SaguenayLac-St-Jean) 200 to $300 \mathrm{~km}$. However, installations should be appropriate for consultation and imaging facilities should be easily accessible. Nevertheless, in a small team of two, the absence of an individual puts a significant stress load on the one covering the tertiary center. Providing support to the community-based urologists overloaded by adult cancer may help them to provide care for the children in their own region.

In the present study, only $24 \%$ of children referred for phimosis and $36 \%$ for cryptorchidism were ultimately scheduled for surgical intervention. Several had a diagnosis of physiological adherent prepuce or retractile testis followed by conservative management. Those numbers correspond to the Canadian conclusions of McGregor and Metcalfe showing that the vast majority of phimosis references by primary care providers are not treated or are followed conservatively with first-line treatments. ${ }^{12-13}$ The same conclusions were made for cryptorchidism consultations in Canada. ${ }^{14-15}$ Those numbers should question the medical students training and the continuous medical education 
provided to primary care providers including the nurse practitioners, as urology rotation is optional in the province of Quebec. Several educational measures on the subjects of preputial and testicular pathophysiology are worthwhile. Urological rotations, conferences, videos and brochures are useful ways to strengthen the urological knowledge of primary care physicians.

The results of our study should be interpreted in the light of some limitations. First, the retrospective nature of this study introduces selection and information bias. Some patients were referred for more than a single urological problem but only the main problem was accounted for. Some other patients visited more than once in this one-year study for the same medical problem. These biases may have increased the percentages of certain pathologies needing a closer follow-up. We also naturally tend to postpone appointments after the winter season for distant families. Several patients with urological issues were also concomitantly seen by different services like pediatric general surgery and nephrology but those numbers were not captured. In our center, we also try to coordinate several same-day speciality appointments and same-day family appointments. This may mean for example that we have seen a patient with simple phimosis that could have been easily taken care of by the community-based urologist, but he had a scheduled appointment with the pediatric neurosurgeon in Quebec on that day, therefore he was offered an appointment with the pediatric urologist as well. It could also be interesting to survey primary care physicians about the pediatric urological pathologies they encounter and to reinforce their continuous medical education training.

\section{Conclusion}

Because the province of Quebec is the largest in Canada, it's tertiary medical centers must cover large territories. Traveling from remote areas to meet the pediatric urologist brings major organizational and societal costs. The average pediatric patient travels 140 $\mathrm{km}$ round trip to see the urologist. There are many possible improvements to facilitate access to a pediatric urologist. The use of telemedecine can be introduced for specific situations for which a physical examination is not the most important part of the assessment. Community-based consultations should be promoted and on-site consultation by the pediatric urologist should be assessed. Furthermore, improving urological education to primary care providers could help achieve more effective coverage. This reality is applicable to other Canadian provinces and these solutions could be useful for other Canadian tertiary centers and specialties. 


\section{References}

1. Manuel des spécialistes, brochure no1 (no 154), RAMQ; 2014

2. Shivji S, Metcalfe P, Khan A et al. Pediatric surgery telehealth: patient and clinician satisfaction. Pediatr Surg Int 2011 ; 27:523-26.

3. X. Bator E, M. Gleason J, J. Lorenzo A et al. The burden of attending a pediatric surgical clinic and family preferences toward telemedicine. Journal of Pediatric Surgery 502015 ; 1776-82.

4. Guide de facturation rémunération à l'acte, RAMQ ; septembre 2018.

5. Le médecin, la télémédecine et les technologies de l'information et de la communication, Guide d'exercice, Collège des médecins du Québec ; 2015.

6. Infolettre Modification 63 à l'Accord-cadre, RAMQ ; 2012.

7. Raison N, Shamim Khan M, Challacombe B. Telemedicine in Surgery: What are the Opportunities and Hurdles to Realising the Potential? Curr Urol Rep 2015 ; 16: 43.

8. Ellimoottil C, Skolarus T, Gettman M et al. Telemedicine in Urology: State of the Art. Elsevier UROLOGY 94: 10-16, 2016.

9. J. Andino J, Guduguntla V, Welzer A et al. Examining the Value of Video Visits to Patients in an Outpatient Urology Clinic. Elsevier UROLOGY 110: 31-35, 2017.

10. R. Viers B, Pruthi S, E. Rivera M et al. Are Patients Willing to Engage in Telemedicine for Their Care: A Survey of Preuse Perceptions and Acceptance of Remote Video Visits in a Urological Patient Population. Elsevier UROLOGY 83: 1233-40, 2015.

11. Mozafarpour S, Abbasioun R, Kajbafzadeh A-M. The mobile technology era: Potential benefits in pediatric urology. Journal of Pediatric Urology 2017 ; 13, 529e530.

12. McGregor TB, Pike JG, Leonard MP. Phimosis--a diagnostic dilemma? Canadian Journal of Urology $2005 ; 12(2): 2598-602$.

13. D. Metcalfe P, Elyas R. Foreskin management. Canadian Family Physician 2010 ; 56:e290-5.

14. Attalla K, Amone E, Williot P et al. Cryptorchidism: experience and reason. Canadian Journal of Urology 2017 ; 24(4) :8941-45.

15. LP. Romao R. Pediatric urologists must advocate for improved quality of care in patients with cryptorchidism. Canadian Urological Association Journal 2017 ; 11(1-2Suppl1):S33. 
Figures and Tables

\begin{tabular}{|l|c|}
\hline \multicolumn{2}{|l|}{ Table 1. Most frequent urological pediatric reason for consultation } \\
\hline Reason for consultation & \% of all consultations \\
\hline Postoperative & 14.66 \\
\hline Phimosis & 14.19 \\
\hline Enuresia & 13.88 \\
\hline Hydronephrosis & 13.27 \\
\hline Micturition disorder other than enuresia & 10.64 \\
\hline Cryptorchidism and retractile testis & 8.01 \\
\hline Vesicoureteral reflux & 4.10 \\
\hline $\begin{array}{l}\text { Hydrocele, varicocele, and scrotal } \\
\text { anomalies }\end{array}$ & 3.38 \\
\hline Others & 17.87 \\
\hline
\end{tabular}

